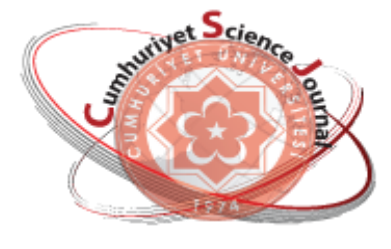

e-ISSN: $2587-246 X$

ISSN: $2587-2680$

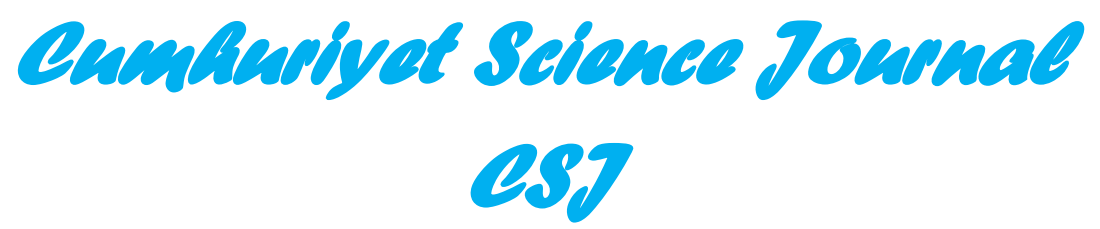

Cumhuriyet Sci. J., Vol.40-3(2019) 723-731

\title{
Novel Fluorene and Pyrrole Comprising Copolymers: Effect of Copolymer Feed Ratio on Electrochromic and Electrochemical Properties
}

\author{
Serife O. HACIOGLU ${ }^{1, *}$ \\ ${ }^{1}$ Iskenderun Technical University, Department of Engineering Science, 31200, Hatay, Turkey \\ Received: 18.03.2019; Accepted: 05.08.2019 \\ http://dx.doi.org/10.17776/csj.541338
}

\begin{abstract}
Herein, synthesis of two homopolymers namely, poly-2,2'-(9,9-dioctyl-9h-fluorene-2,7diyl)bisthiophene (PBT), poly-pyrrole-3-carboxylic acid (PP3CA) and fluorene and pyrrole comprising five novel copolymers ( $\mathrm{CoP} 1, \mathrm{CoP} 2, \mathrm{CoP} 3, \mathrm{CoP} 4, \mathrm{CoP} 5)$ were electrochemically synthesized. Each electrolytic solution was prepared with different monomer feed ratios to investigate the effect of comonomer ratio on electrochromic and electrochemical properties. After synthesis, homopolymers and copolymers were compared in terms of their electrochemical, spectroelectrochemical and colorimetry properties. The number of studies on electrochromic characterization of pristine P3CA group was limited in literature, hence in this study P3CA was electrochemically inserted into the polymer chain via copolymerization.CoP1 with 1:1 (BT: P3CA) monomer feed ratio exhibited the lower optical band gap and red shifted neutral state absorption compared to PP3CA, additionally light yellow color of PP3CA turned out to be multichromic for CoP1 with the insertion of BT unit via electrocopolymerization.
\end{abstract}

Keywords: Fluorene, pyrrole, copolymerization, electrochromism

Fluoren ve Pirol İçeren Kopolimerler: Kopolimer Besleme Oranının Elektrokimyasal ve Elektrokromik Özellikler Üzerine Etkisi

\begin{abstract}
Özet. Bu çalışmada, poli-2,2'-(9,9-dioktil-9h-fluoren-2,7-diyl)bistiyofen (PBT) ve poli-pirol-3-karboksilik asit (PP3CA) olarak adlandırılan iki polimerin ve ayrıca fluoren ve pirol gruplarını içeren 5 tane yeni kopolimerin (CoP1, CoP2, CoP3, CoP4, CoP5) sentezi elektrokimyasal yöntemlerle gerçekleştirilmiştir. Kopolimer çözeltileri BT ve P3CA monomerlerinin farklı besleme oranlarında karışımı ile hazırlanarak, monomer besleme oranının kopolimerin elektrokimyasal ve elektrokromik özellikleri üzerine etkisi incelenmiştir. Elektrokimyasal polimer sentezlerinin ardından tüm homopolimer ve kopolimerlerin elektrokimyasal, elektrokromik ve kolorimetrik çalışmaları yapılmıştır. Literatürde P3CA monomerinin elektrokromik çalışmalarının az olması nedeniyle, bu yapı BT monomeri ile beraber kopolimer zincirine katılmıştır. Kopolimerler içinde, 1:1 (BT: P3CA) monomer besleme oranı ile hazırlanan CoP1 kopolimeri, PP3CA homopolimeri ile kıyaslandığında daha düşük bant aralığı ve multikromik özellikler göstermiştir.
\end{abstract}

Anahtar Kelimeler: Fluoren, pirol, kopolimerizasyon, elektrokromizm

\section{INTRODUCTION}

Electrochromic polymers are types of organic materials which can change their colors with applied potential have gained a great attention in recent years especially for many display and optoelectronic applications. In addition, electrochromism could be achieved with very low potential difference which strongly depends on the structure of the polymers. Although many inorganic molecules and organic compounds were widely used as electrochromic materials, organic conducting polymers (CPs) have drawn great interest due to their superior properties, such as relatively low cost, easy structural modification via chemical synthesis, color tunability, fast switching 
time and high coloration efficiency [1-5]. As a result of these attractive properties, CPs have been used not only for electrochromic applications but also in wide range of technological areas such as organic photovoltaics (OPVs), organic light emitting diodes (OLEDs), field effect transistors (FETs), sensors and super capacitors (SCs) over the last two decades [6-10]. In order to use the CPs for the abovementioned applications, the value of the band gap and corresponding HOMO-LUMO energy levels are crucial factors. In recent years, the synthesis of multipurpose smart polymers with enhanced electronic and optical properties are the main purpose of the researchers in this field and this purpose can be achieved with controlling the structural alterations [11].

In literature, bond length alternation, planarity, interchain alternation, resonance effect, diverse pendant groups and donor-acceptor theory were well known strategies for controlling electronic and optoelectronic features of CPs, however donoracceptor approach is considered as the most proper one to design CPs with unique and enhanced physicochemical properties. [12-14] Combination of different donor and acceptor units in the polymer backbone yields multipurpose copolymers with enhanced electrochemical and optical properties such as switching time, neutral and oxidized state colors and coloration efficiency. Another popular strategy for structural modification is copolymerization of different monomers. Via copolymerization, physicochemical behaviors could be altered easily and the units which can not be polymerized could be inserted into the polymer backbone [15,16]. Copolymerizationcan be performed via chemically or electrochemically in the presence of at least two comonomers with different monomer feed ratios. When compared to chemical copolymerization, electrochemical one has some certain advantages such as simplicity, easy and fast polymer synthesis and synthesis of well adhered copolymer film on an electrode surface. Additionally, after electrocopolymerization the electro-optical behaviors of the resulting copolymer films could be investigated with the same electrode easily [17].

In literature, different type of units such as; benzothiadiazole (BTd), quinoxaline (Qx), benzotriazole $(\mathrm{BTz})$, carbazole $(\mathrm{Cz})$, bithiophene, propylenedioxythiophene (ProDOT), fluorene and 3,4 ethylene dioxythiophene (EDOT) were widely used for electrochemical copolymerization and electrochromic applications. [18-20] Among a great deal of electroactive polymers, polyfluorenes aroused interest as a blue light emitter with their high thermal and chemical stability and photostability both in solution and solid state. [21] However, some crucial drawbacks such as; poor solubility, aggregation in the solid state and high energy barrier for hole injection limited the possible application fields of PF. Copolymerization of fluorene with different comonomers resulted multipurpose functional copolymers with enlarged application fields [22,23]. Another interesting and popular comonomer unit is pyrrole (Py) due to some certain structural advantages such as; high electrical conductivity, easy preparation, chemical stability, structural versatility and biocompatibility. These unique properties increased the applicability of Py comprising polymers in different fields especially electrochemical and biological applications [2426].

In the light of these, the main purpose of this study is to combine the promising properties of fluorene and Py monomers via electrochemical copolymerization technique. Herein, syntheses of two homopolymers (PBT and PP3CA) and design of five novel copolymers (CoP1, CoP2, CoP3, CoP4, CoP5) of BT and P3CA in different monomer feed ratios were performed. The electrochomical, spectroelectrochemical and colorimetric properties of resulting homopolymers and copolymers were explored and reported. Finally, the effect of copolymer feed ratio on electrochromic and electrochemical properties were also discussed.

\section{EXPERIMENTAL}

\subsection{Materials and Equipments}

2,2'-(9,9-Dioctyl-9h-Fluorene-2,7-Diyl)bisthio phene (BT), pyrrole-3-carboxylic (P3CA) (Fig. 1) are commercially available monomers and purchased from Sigma- Aldrich Chemical Co. Ltd. and used without any further purification. GAMRY 600 potentiostat/galvanostat was used for cyclic voltammetry studies and UV-Vis spectra characterizations were monitored at ambient temperature and conditions via Varian Carry 5000 $\mathrm{UV}$-Vis spectrophotometer. 
(a)

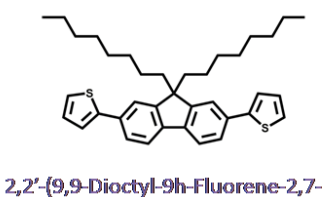

Divl) Bisisthiophene (b)

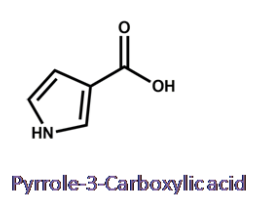

Figure 1. Molecular structures of 2,2'-(9,9-Dioctyl-9hfluorene-2,7-diyl)bisthiophene (BT), pyrrole-3-carboxylic acid (P3CA).

\section{RESULTS AND DISCUSSIONS}

\subsection{Electrochemical copolymerization and} characterizations

Cyclic Voltammetry (CV) is a very useful and widely used technique to determine the electroactivity of the compounds and also for quantitative analysis such as; HOMO-LUMO energy levels and oxidation/reduction potentials. Besides, electrochemical polymerization could be performed via $\mathrm{CV}$ with simple chemicals.

In this study electrochemical polymerizations for both homopolymers PBT $(0.01 \mathrm{M})$ and PP3CA $(0.01 \mathrm{M})$ and copolymers CoP1, CoP2, CoP3, CoP4, CoP5 (with a monomer feed ratio (PBT: P3CA) 1:1, 1:3, 1:5, 3:1 and 5:1) were performed via $\mathrm{CV}$ in $0.1 \mathrm{M} \mathrm{LiClO}_{4}-\mathrm{NaClO}_{4} / \mathrm{ACN}$ electrolyte/solvent couple. Both electropolymerizations were performed in a three electrode system comprising ITO coated glass slide (the working electrode), platinum wires (the counter electrode) and $\mathrm{Ag}$ wire (the pseudo reference electrode).The monomer structures and $\mathrm{CVs}$ for electrochemical polymerization of $\mathrm{BT}$ and P3CA are depicted in Figure 2. For electrochemical copolymerization, the compatibility of the oxidation potentials for two different monomers are vital for efficient copolymer film synthesis. As seen, in the first cycle of the $\mathrm{CV}$, an irreversible monomer oxidation peaks were recorded at $1.18 \mathrm{~V}$ and $1.13 \mathrm{~V}$, respectively. These similar oxidation potentials make BT and P3CA good candidates for copolymerization studies. During the $\mathrm{CV}$, the increase in the current response indicates the successful electrochemical polymerization as the cycle number increased.
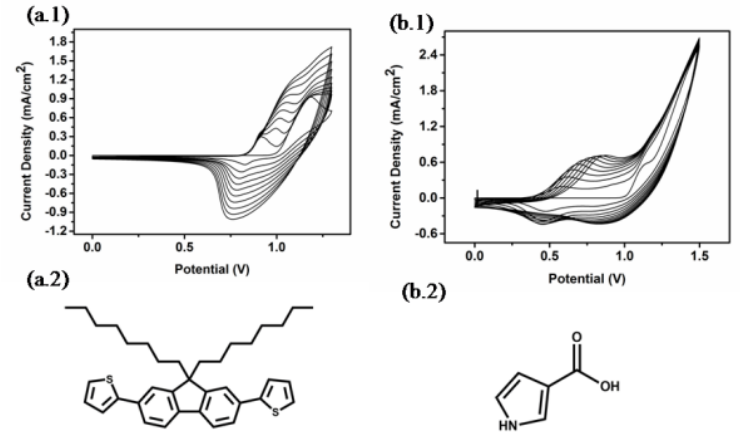

Figure 2. Cyclic voltammograms of $\mathrm{BT}$ and $\mathrm{P} 3 \mathrm{CA}$ in $0.1 \mathrm{M}$ $\mathrm{LiClO}_{4}-\mathrm{NaClO}_{4} / \mathrm{ACN}$ solution at a scan rate of $100 \mathrm{mV} . \mathrm{s}^{-1}$ with corresponding monomer structures.

After electrochemical polymerization, single scan CVs were recorded in a monomer free medium for both homopolymers and corresponding oxidation peaks were obtained at $1.00 \mathrm{~V}$ and $0.75 \mathrm{~V}$ with 0.79 $\mathrm{V}$ and $0.44 \mathrm{~V}$ onset potentials, respectively (Figure 5). The HOMO-LUMO energy levels of the electroactive polymers were very crucial to test their applicability in different fields, for this reason HOMO energy levels of each homopolymers were calculated from the onsets of the corresponding oxidation potentials as $-5.54 \mathrm{eV}$ for PBT and -5.19 $\mathrm{eV}$ for PP3CA. Eqn 1 was used for HOMO energy level calculations and the results were summarized in Table 1.

$H O M O=-\left(4.75 \mathrm{eV}+E_{\text {onset }}{ }^{o x}\right)$

Eqn.1

In literature, P3CA derivatives were widely used for biological applications [27-28]. Herein, copolymerization technique was used to enhance the electrochemical behaviors of P3CA comprising electroactive polymers. As mentioned before, the compatibility of the oxidation potentials for monomers are very important for efficient copolymerization, in this study PBT monomer was used as a second monomer and five different copolymers (CoP1, CoP2, CoP3, CoP4, CoP5) with 1:1, 1:3, 1:5, 3:1 and 5:1 (PBT: P3CA) monomer feed ratios were synthesized electrochemically. Comonomer feed ratios of PBT: PP3CA were decided in order to investigate the effect of P3CA and BT units on electrochromic behaviors in detail. For that purpose initially CoP1 with 1:1 comonomer feed ratio was synthesized, then the effect of increasing P3CA and BT units on electrochromic characters were investigated stepwise. 1:5 and 5:1 comonomer feed ratios were chosen as the limit since after this ratio the copolymers exhibited PPBT and PP3CA like characters. Similar to the preparation of homopolymers, $0.1 \mathrm{M} \mathrm{LiClO}_{4}-\mathrm{NaClO}_{4} / \mathrm{ACN}$ 
electrolyte/solvent system was used for electrochemical copolymerization. As seen in Figure 3 and Figure 4, an increase in anodic and cathodic current densities were observed for all copolymers which prove the continuous copolymerization and the deposition of copolymer films on ITO coated glass slides. Then single scan $\mathrm{CVs}$ were recorded for all copolymers in a monomer free medium. From single scan CVs, oxidation potentials were calculated as $0.79 / 1.05 \mathrm{~V}$ (CoP1), 0.53/0.98 V (CoP2), $0.83 \mathrm{~V}$ (CoP3), 0.76/1.05 V (CoP4) and 0.80/1.10 V (CoP5). Besides, corresponding HOMO energy levels were calculated from Eqn 1 and reported in Table 1 as 5.31eV(CoP1), -5.04 eV(CoP2), -5.29 eV(CoP3), $5.60 \mathrm{eV}(\mathrm{CoP} 4)$ and $-5.61 \mathrm{eV}(\mathrm{CoP} 5)$, respectively. As seen, two oxidation potentials at around $0.75 \mathrm{~V}$ and $1.00 \mathrm{~V}$ were observed for CoP1, CoP2, CoP4 and $\mathrm{CoP} 5$ which prove the successful insertion of comonomer units (BT and P3CA) into the copolymer chains. $\mathrm{CV}$ s of all copolymers (CoP1, $\mathrm{CoP} 2, \mathrm{CoP} 3, \mathrm{CoP} 4$ and CoP5) for both electrochemical copolymerizations and single scans recorded in a monomer free medium were reported in Figure 3 and Figure 4.
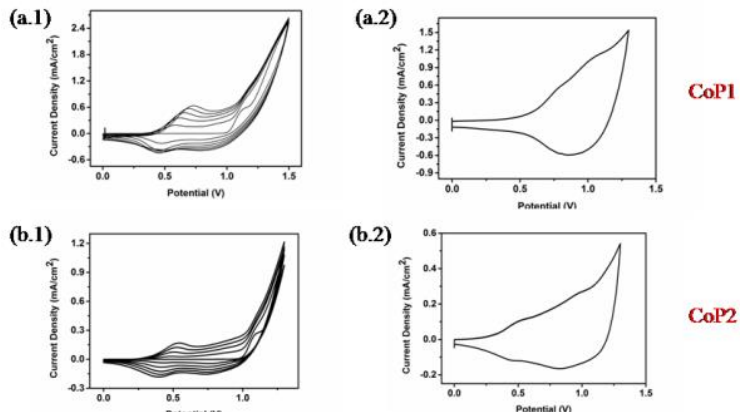

(b.2)

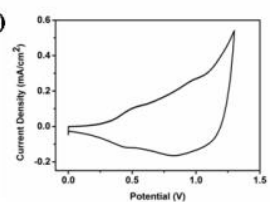

$\mathrm{CoP} 2$
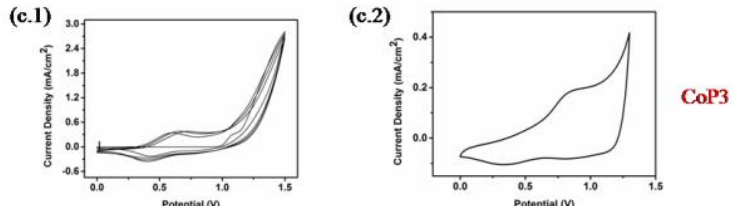

Figure 3. Cyclic voltammograms of (a.1) CoP1 (b.1) CoP2 (c.1) CoP3 during the electropolymerization on ITO- coated glass electrode and (a.2, b.2, c.2) single scan cyclic voltammograms of the resulting copolymers.

Cyclic voltammograms of $\mathrm{CoP} 1, \mathrm{CoP} 2$ and $\mathrm{CoP} 3$ during the electropolymerization and single scan $\mathrm{CVs}$ of the resulting copolymers were depicted in Figure 3. As seen, CoP1 with 1:1 (BT:P3CA) comonomer feed ratio exhibited two oxidation peaks at $0.79 \mathrm{~V}$ and $1.05 \mathrm{~V}$ with higher current density compared to those of $\mathrm{CoP} 2$ and $\mathrm{CoP} 3$. When P3CA ratio was increased into the copolymer chain, electroactivity of CVs depleted with lower current density as seen in single scan
CVs which can be dedicated to the poor electroactive character of P3CA.
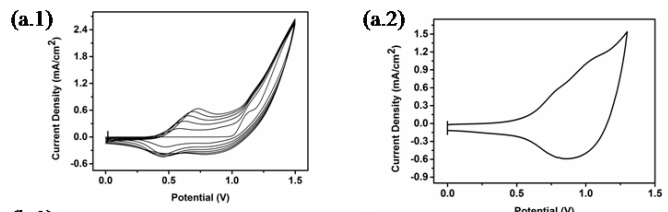

CoPI
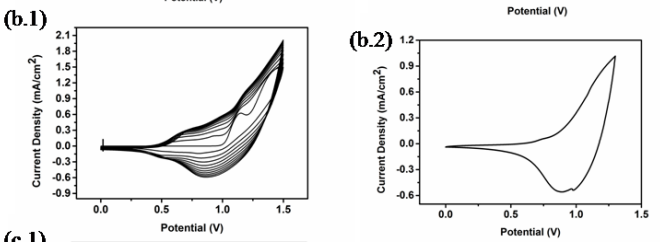

CoP4
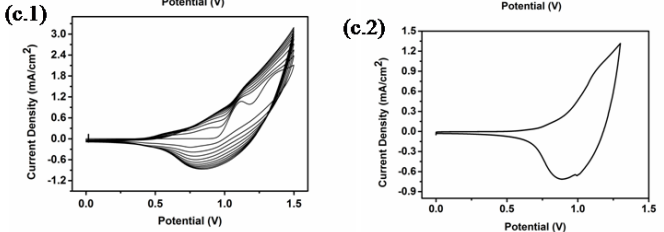

CoPs

Figure 4. Cyclic voltammograms of (a.1) $\mathrm{CoP} 1$ (b.1) $\mathrm{CoP} 4$ (c.1) CoP5 during the electropolymerization and (a.2, b.2, c.2) single scan cyclic voltammograms of the resulting copolymers.

Cyclic voltammograms of CoP1, CoP4 and CoP5 during the electropolymerization and single scan cyclic voltammograms of the resulting copolymers were illustrated in Figure 4. As seen, the increasing amount of BT unit into copolymer chain affected electrochemical behaviors positively with increasing current density and electroactivity. Besides, as mentioned before copolymers exhibited two oxidation potentials at around $0.75 \mathrm{~V}$ and 1.00 $\mathrm{V}$ arising from $\mathrm{P} 3 \mathrm{CA}$ and $\mathrm{BT}$ comonomers, respectively. As BT comonomer feed ratio was increased from $\mathrm{CoP} 1$ to $\mathrm{CoP} 5$, the intensity of the latter one increased significantly which proves the increasing number of BT unit into the copolymer chain. (Figure 4)

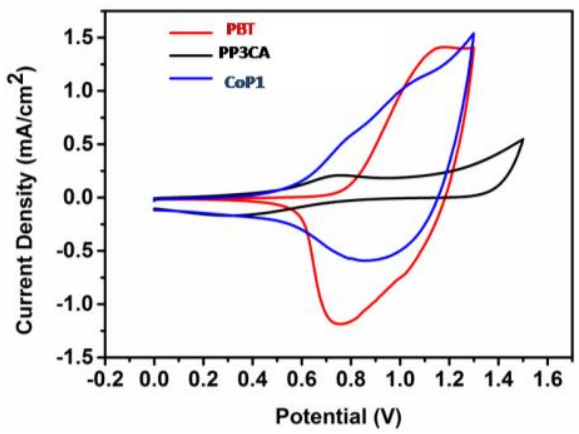

Figure 5. Single scan cyclic voltammograms for PBT, PP3CA and CoP1.

In order to investigate the effect of different comonomer units (P3CA and BT) on electrochemical behaviors, single scan CVs for PBT, PP3CA and CoP1 were recorded and reported in Figure 5. As mentioned before, BT unit was 
inserted into the copolymer structure in order to improve the electrochemical behaviors and as seen in Figure 5, CoP1 exhibited higher current density and higher electroactivity compared to those of
PP3CA which enlarge the application fields of P3CA comprising copolymers

Table 1. Summary of electrochemical and spectroelectrochemical properties of PBT, PP3CA and corresponding copolymers

\begin{tabular}{|c|c|c|c|c|c|c|c|c|}
\hline & $\begin{array}{l}\text { Monomer } \\
\text { feed ratio } \\
\text { (BT: } \\
\text { P3CA) }\end{array}$ & $\begin{array}{l}\mathrm{E}_{\text {ox }}^{\text {mon }} \\
\text { (V) }\end{array}$ & $\begin{array}{l}E_{p \text {-doping }} \\
(V)\end{array}$ & $\begin{array}{l}\mathrm{E}^{\mathrm{ox}} \text { onset } \\
(\mathrm{V})\end{array}$ & $\begin{array}{l}\text { HOMO } \\
(\mathrm{eV})\end{array}$ & $\begin{array}{l}\lambda_{\max } \\
(\mathrm{nm})\end{array}$ & $\begin{array}{l}\lambda_{\max }{ }^{\text {onset }} \\
(\mathrm{nm})\end{array}$ & $\begin{array}{l}\mathrm{E}_{\mathrm{g}}^{\mathrm{op}} \\
(\mathrm{eV})\end{array}$ \\
\hline PBT & $1: 0$ & 1.18 & 1.00 & 0.79 & -5.54 & 430 & 540 & 2.29 \\
\hline PP3CA & 0:1 & 1.13 & 0.75 & 0.44 & -5.19 & 397 & 600 & 2.07 \\
\hline CoP1 & 1:1 & - & $0.79 / 1.05$ & 0.56 & -5.31 & 412 & 650 & 1.91 \\
\hline $\mathrm{CoP} 2$ & $1: 3$ & - & 0.53/0.98 & 0.29 & -5.04 & 420 & 560 & 2.21 \\
\hline $\mathrm{CoP} 3$ & $1: 5$ & - & 0.83 & 0.54 & -5.29 & 400 & 611 & 2.03 \\
\hline CoP4 & $3: 1$ & - & $0.76 / 1.05$ & 0.85 & -5.60 & 419 & 584 & 2.12 \\
\hline CoP5 & $5: 1$ & - & $0.80 / 1.10$ & 0.86 & -5.61 & 424 & 628 & 1.98 \\
\hline
\end{tabular}

\subsection{Spectroscopic Characterization}

After electrochemical copolymerization and characterizations, the spectral behaviors were recorded with UV-VIS spectrophotometer in order to investigate the electronic transitions and changes in optical properties upon applied potential. The effect of the changing monomer feed ratio on the optoelectronic properties of the fluorene and pyrrole comprising electroactive copolymers were examined by spectroelectrochemical studies. In addition, from these studies some crucial parameters such as; maximum absorption wavelengths $\left(\lambda_{\max }\right)$, optical band gap and polaron/bipolaron bands were determined.

Before stepwise oxidation, electrochemically synthesized copolymer films were reduced to neutral states by applying a constant potential to remove any trapped charge and dopant ions. Then, the neutral films were oxidized stepwise and electronic absorption spectra were recorded in a monomer free $0.1 \mathrm{M} \mathrm{LiClO}_{4}-\mathrm{NaClO}_{4} / \mathrm{ACN}$ solution.

As seen in Figure 6 and Figure 7, the maximum absorption wavelengths $\left(\lambda_{\max }\right)$ for homopolymers and copolymers were centered at $430 \mathrm{~nm}$ (PBT), $397 \mathrm{~nm}$ (PP3CA), $412 \mathrm{~nm}$ (CoP1), $420 \mathrm{~nm}$ (CoP2), $400 \mathrm{~nm}$ (CoP3), $419 \mathrm{~nm}(\mathrm{CoP} 4), 424 \mathrm{~nm}$ (CoP5). As mentioned before the P3CA homopolymer exhibited poor electrochemical behaviors, in addition the neutral state absorption of P3CA was centered in the UV region which limit the application fields. In this study, insertion of fluorene derivatives into the copolymer structure with different monomer feed ratios enhanced the electrochromic and spectroelectrochemical behaviors. As seen in Figure 6, while P3CA homopolymer showed light yellow color both in the neutral and oxidized states, CoP1 with 1:1 (BT: P3CA) monomer feed ratio exhibited multichromic behavior. While homopolymers showed $\lambda_{\max }$ values centered at $430 \mathrm{~nm}$ (PBT) and $397 \mathrm{~nm}$ (PP3CA), all copolymers exhibited $\lambda_{\max }$ values between those values, additionally as the P3CA feed ratio was increased in the copolymer structure an obvious red shift was observed.

During spectroelectrochemical measurements, new absorption bands were observed at around $700 \mathrm{~nm}$ for both homopolymers and copolymers due to the formation of charge carriers named as polarons (radical cations) on the polymer backbone. During stepwise oxidation, the intensity of the polarons increased significantly, meanwhile the intensity of the neutral state absorptions gradually diminished.

Another important parameter of electroactive polymers for variety of applications is the optical band gap value which can be calculated from neutral state absorption. Herein, optical band gaps of both homopolymers and copolymers were determined from the onset of their lowest energy $\pi$ $\pi^{*}$ transitions as $2.29 \mathrm{eV}$ (PBT), $2.07 \mathrm{eV}$ (PP3CA), $1.91 \mathrm{eV}$ (CoP1), $2.21 \mathrm{eV}$ (CoP1), $2.03 \mathrm{eV}$ (CoP1), $2.12 \mathrm{eV}$ (CoP1), $1.98 \mathrm{eV}$ (CoP1), respectively. When homopolymers and copolymers were compared in terms of optical characters, while PBT 
exhibited the highest optical band gap due to its UV-region covered absorption, CoP1 with 1:1 (BT: P3CA) monomer feed ratio showed the lowest optical band gap due to its red shifted absorption. (a)

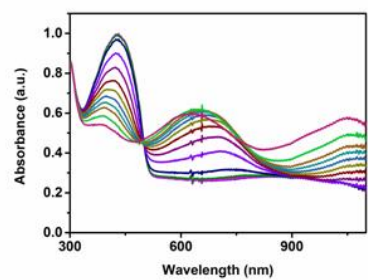

(b)

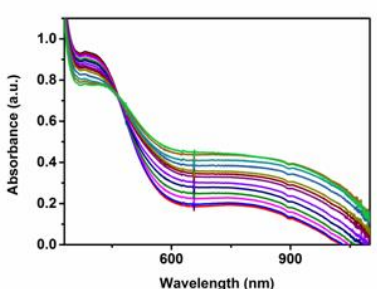

(c)

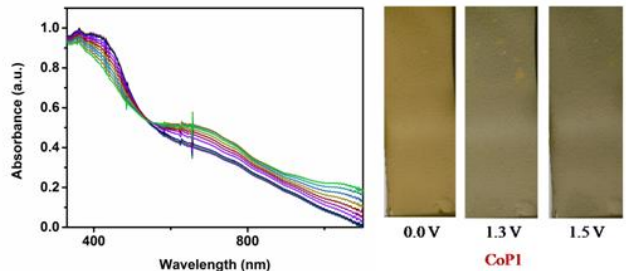

Figure 6. UV-Vis spectra of (a) PBT (b) PP3CA and (c) CoP1 during a slow oxidation process in a $0.1 \mathrm{M} \mathrm{LiClO} 4-\mathrm{NaClO} 4$ IACN monomer-free solution with corresponding colors in the neutral and oxidized states.
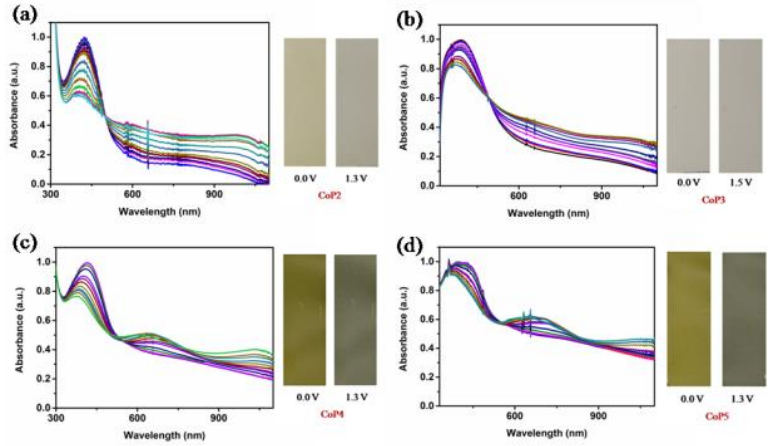

Figure 7. UV-Vis spectra of (a) $\mathrm{CoP} 2$ (b) $\mathrm{CoP} 3$ (c) $\mathrm{CoP} 4$ and (d) CoP5 during stepwise oxidation in a $0.1 \mathrm{M} \mathrm{LiClO4-}$ $\mathrm{NaClO} 4 / \mathrm{ACN}$ monomer-free solution with corresponding colors in the neutral and oxidized states.

Finally, colorimetric studies were performed in order to report the colors of all copolymers both in the neutral and oxidized states. For colorimetric studies photographs of the polymers films were recorded and reported in Table 2 with the corresponding $\mathrm{L}, \mathrm{a}, \mathrm{b}$ values according to $\mathrm{CIE}$ (Commission Internationale de l'Eclairage) coordinates. CIE coordinates were widely used to report the colors of materials in a more scientific way. While ' $L$ ' represents the brightness of the color, 'a' represents the color between red/magenta and green and ' $\mathrm{b}$ ' represents the color between yellow and blue in the colorimetric measurements, The corresponding L, a, b results for both homopolymers and copolymers were reported in Table 2. As mentioned before, the light yellow color of P3CA homopolymer observed both in the neutral and oxidized states were changed to multichromic behavior via insertion of BT unit into the copolymer chain with 1:1 (BT: P3CA) monomer feed ratio. Additionally, lower optical band gap and red shifted neutral state absorption were investigated for CoP1. In this study P3CA group was electrochemically inserted into the copolymer chain with copolymerization technique, and as a separate study the P3CA comprising copolymers will be used for biosensor applications in our research group. 
Table 2. Colorimetric measurements of the homopolymers and copolymers.

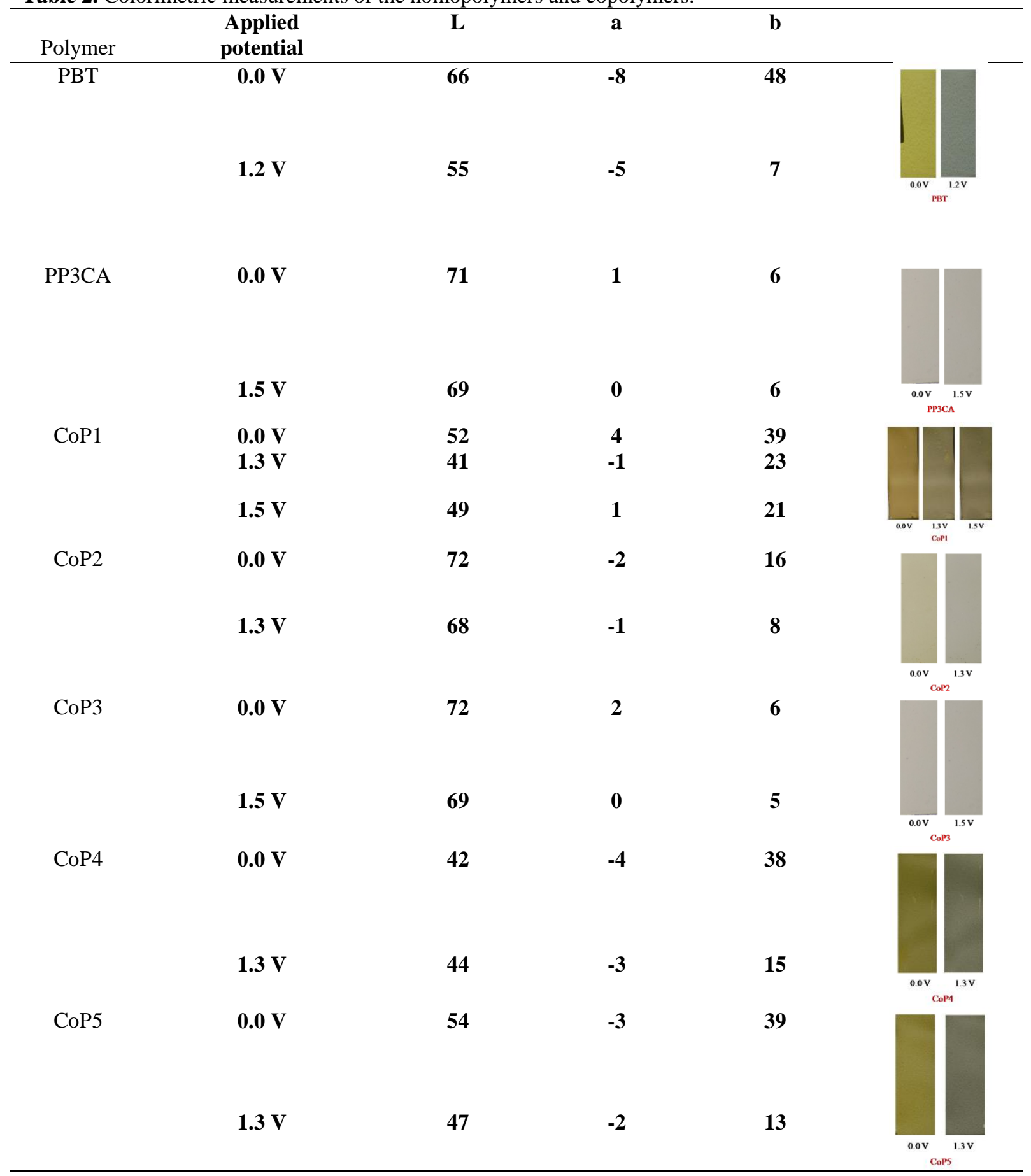

\section{CONCLUSION}

Fluorene and pyrrole bearing electrochromic homopolymers (PBT and PP3CA) and novel copolymers (CoP1, CoP2, CoP3, CoP4, CoP5) with different monomer feed ratios were synthesized via electrochemical technique. After successive electropolymerization, the electrochemical, spectroelectrochemical and colorimetric properties were investigated for all polymers. All copolymers exhibited different electrochemical and optical properties when compared to their homopolymers. While homopolymers PBT and PP3CA exhibited $\lambda_{\max }$ values centered at $430 \mathrm{~nm}$ and $397 \mathrm{~nm}$, all copolymers exhibited $\lambda_{\max }$ values between those values. In addition, in terms of optical behaviors as 
the P3CA feed ratio was increased in the copolymer structure the obvious red shift was observed on spectroelectrochemical characterizations. While PBT showed yellow and green colors in the neutral and oxidized states, the light yellow color was observed for P3CA in both states. However multichromic behavior was explored for $\mathrm{CoP} 1$ via insertion of BT unit into the copolymer chain with 1:1 (BT: P3CA) monomer feed ratio. Additionally, lower optical band gap and red shifted neutral state absorption were investigated for CoP1 compared with pristine PP3CA. Finally, in this study P3CA group was electrochemically inserted into the copolymer chain successfully and electrochromic characters were investigated in detail, in future the P3CA bearing copolymers will be used for biosensor applications in our research group.

\section{ACKNOWLEDGMENTS}

I would like to thank and appreciate Prof. Dr. Levent Toppare (Department of Chemistry, Middle East Technical University, Turkey) for his guidance and support for my academic carrier.

\section{REFERENCES}

[1] Sonmez G., Shen C.K.F., Rubin Y. and Wudl F., A red, green, and blue (RGB) polymeric electrochromic device (PECD): the dawning of the PECD era, Angew. Chem. Int. Ed., 43 (2004) 1498-502.

[2] Xu G., Zhao J., Liu J., Cui C., Hou Y. and Kong Y., Electrochemical synthesis and characterization of imidazole-containing polymers, and their electrochromic devices application organic and bioelectrochemistry, J. Electrochem Soc, 160(11), (2013) G149-G155.

[3] Kumar A., Welsh D.M., Morvant M.C., Piroux F., Abboud K.A. and Reynolds J.R., Conducting poly(3,4-alkylenedioxythiophene) derivatives as fast electrochromics with highcontrast ratios, Chem. Mater. 10 (1998) 896902.

[4] Balan A., Gunbas G., Durmus A. and Toppare L., Donor-acceptor polymer with benzotriazole moiety: enhancing the electrochromic properties of the "donor unit", Chem. Mater. 20 (2008) 7510-7513.

[5] Krebs E.F.C., Electrochromic displays: The new black, Nat. Mater. 7 (2008) 766-767.

[6] Yang C., Kim J. Y., Cho S., Lee J. K., Heeger A. J. and Wudl F., Functionalized methanofullerenes used as n-type materials in bulk-heterojunction polymer solar cells and in field-effect transistors, J. Am. Chem. Soc., 130 (2008) 6444-6450.

[7] Ma C., Toya M. and Xu C., Flexible electrochromic device based on poly (3,4-(2,2dimethylpropylenedioxy)thiophene), Electrochim. Acta 54 (2008) 598-605.

[8] Soylemez S., Hacioglu S.O., Kesik M., Unay H., Cirpan A. and Toppare L., A novel and effective surface design: conducting polymer/ $\beta$ cyclodextrin host-guest system for cholesterol biosensor, ACS Appl. Mater. Interfaces, 6 (2014) 18290-18300.

[9] Xu Z.,Yu D. and Yu M.,The synthesis and photoluminescence characteristics of novel 4aryl substituted thiophene derivatives with bisdiarylacrylonitrile unit, Dyes and Pigments, 95 (2012) 358-364.

[10] Ermiş E., Yigit D. and Güllü M., Synthesis of poly(N-alkyl-3,4-dihydrothieno[3,4-

b] [1,4]oxazine) derivatives and investigation of their supercapacitive performances for charge storage applications, Electrochim. Acta, 90 (2013) 623-633.

[11] Mullekom H. A. M., Vekemans J. A. J. M., Havinga E. E. and Meijer E. W., Developments in the chemistry and band gap engineering of donor- acceptor substituted conjugated polymers, Mater. Sci. Eng., R32 (2001) 1-40.

[12] Zhang C., Hua C., Wang G., Ouyang M. and Ma C., A novel multichromic copolymer of 1,4bis(3-hexylthiophen-2-yl)benzene and 3,4ethylenedioxythiophene prepared via electrocopolymerization, J. Electroanal. Chem., 645 (2010) 50-57.

[13] Roncali J., Molecular Engineering of the Band Gap of $\pi$-Conjugated Systems: Facing Technological Applications, Macromol. Rapid Commun., 28 (2007) 1761-1775.

[14] Gunbas G. and Toppare L., Green as it Gets; Donor-Acceptor type Polymers as the Key to Realization of RGB Based Polymer Display Devices, Macromol. Symp., 297 (2010) 79-86.

[15] Nie, G., Qu, L., Xu J. and Zhang S., Electrosyntheses and characterizations of a new soluble conducting copolymer of 5-cyanoindole and 3,4-ethylenedioxythiophene, Electrochim. Acta, 53 (2008) 8351-8358.

[16] Soylemez S., Hacioglu S. O., Uzun S. D. and Toppare L., A low band gap benzimidazole derivative and its copolymer with 3,4ethylenedioxythiophene for electrochemical studies. J. Electrochem. Soc., 162 (1) (2015) H6-H14. 
[17] Aydin A. and Kaya I., Syntheses of novel copolymers containing carbazole and their electrochromic properties, J. Electroanal. Chem., 691 (2013) 1-12.

[18] Kuo C.-W., Wu T.-L., Lin Y.-C., Chang J.-K., Chen H.-R. and Wu T.-Y., Copolymers based on 1,3-bis(carbazol-9-yl)benzene and three 3,4ethylenedioxythiophene derivatives as potential anodically coloring copolymers in high-contrast electrochromic devices, Polymers, 8 (2016) 368-383.

[19] Carbas B. B., Novel electrochromic copolymers based on 3-3'-dibromo-2-2'-bithiophene and 3,4 ethylene dioxythiophene, Polymer, 113 (2017) 180-186.

[20] Ergun E. G. C., Covering the more visible region by electrochemical copolymerization of carbazole and benzothiadiazole based donoracceptor type monomers, Chinese J. Polym. Sci., 37 (2019) 28-35.

[21] Wu F. I., Shih P. I., Shu C. F., Tung Y. L. and Chi Y., Highly efficient light-emitting diodes based on fluorene copolymer consisting of triarylamine units in the main chain and oxadiazole pendent groups, Macromolecules, 38 (2005) 9028-9036.

[22] Lee J. H., Cho H. J., Cho N. S., Hwang D. H., Kang J. M., Lim E. H., Lee I. J. and Shim H. K., Enhanced efficiency of polyfluorene derivatives: Organic-inorganic hybrid polymer light-emitting diodes, J. Polym. Sci. A: Polym. Chem., 44 (2006) 2943-2954.

[23] Carbas B. B. , Kivrak A. and Önal A. M., A new processable electrochromic polymer based on an electron deficient fluorene derivative with a high coloration efficiency, Electrochim. Acta, 58 (2011) 223- 230.

[24] Toshima N. and Ihata O., Catalytic synthesis of conductive polypyrrole using iron (III) catalyst and molecular oxygen, Synth. Met., 79 (1996) 165-172.

[25] Lee S., Cho M. S. and Nam J. D., New strategy and easy fabrication of solid-state supercapacitor based on polypyrrole and nitrile rubber, J. Nanosci. Nanotechnol., 8 (2008) 4722-4725.

[26] Vaitkuviene A., Kaseta V., Voronovic J., Ramanauskaite G., Biziuleviciene G., Ramanaviciene A. and Ramanavicius A., Evaluation of cytotoxicity of polypyrrole nanoparticles synthesized by oxidative polymerization, J. Hazard Mater., 250 (2013) 167-174.

[27] M.-B. Edyta, Siekiera I., Krolikowska A., Donten M. and Nowicka A. M., Combination of copolymer film (PPy-PPyCOOH) and magnetic nanoparticles as an electroactive and biocompatible platform for electrochemical purposes, Electrochim. Acta, 263 (2018) 454464.

[28] Özcan A. and Ilkbas S., Poly(pyrrole-3carboxylic acid)-modified pencil graphite electrode for the determination of serotonin in biological samples by adsorptive stripping voltammetry, Sens. Actuators B, 215 (2015) 518-524. 